\title{
An Alternative To Test Independence Between Expectations And Disconfirmation Versus The Positive Version Of The Assimilation Theory. An Application To The Case Of Cultural/Heritage Tourism.
}

José-María Montero, Ph.D., University of Castilla-La Mancha, Spain

Gema Fernández-Avilés, Ph.D., University of Castilla-La Mancha, Spain

\begin{abstract}
Despite the emergence of new strategies, models of expectancy/disconfirmation are still very popular in tourist research. This is why they are revisited by presenting an alternative for testing independence between expectations and disconfirmation versus what we call the positive version of the assimilation theory. A derivation of the chi-square statistic including an asymmetric continuity correction is provided to carry out such a test. This article relies on the information given by 1,500 respondents who were given a small questionnaire specially designed to measure tourist satisfaction in the emblematic part of Toledo, Spain (a UNESCO World Heritage City).
\end{abstract}

Keywords: Test Independence, Tourism, World Heritage City

\section{INTRODUCTION}

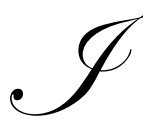
n 2006, the World Travel and Tourism Council (WTTC) demonstrated the tremendous scale of the world's tourism sector (WTTC, 2006) and pointed out that: (i) the travel and tourism industry accounted for $13.2 \%$ of world GDP, (ii) had a turnover of US $\$ 6,477.2$ billion, and (iii) employed 234 million people ( $8.7 \%$ of total world employment). It is therefore clear that tourism is the major force in the economy of the world, an activity of global importance and significance. Moreover, tourism has been remarkable in its resistance to adverse economic and political conditions (Cooper et al., 2008). Events such as the terrorist bombing on $11^{\text {th }}$ September, 2001 and the 2004 Boxing Day Tsunami clearly demonstrate the sector's ability to regroup and place emphasis on a new vocabulary including words such as "safety", "security", "risk management", "crisis" and "recovery". Inevitably though, growth is slowing as the market matures and, as the nature of the tourist and his or her demands change, the sector will need to be creative in supplying products to satisfy the "new tourist".

One particular case of tourism is cultural/heritage tourism, where "cultural/heritage" can be defined as the monuments, buildings and archaeological sites of outstanding universal value from the point of view of history, art or science (Huh, 2002).

Cultural/heritage tourism is the fastest growing segment of the tourism industry, and obviously, the growth in the cultural/heritage tourism market may provide several benefits to cultural/heritage destinations. Because of people's inclination to seek out novel attractions, including traditional cultures, heritage tourism has become a major "new" area of tourism demand, which almost all policy-makers are now aware of and anxious to develop. Heritage tourism, as part of the broader category of "cultural tourism", is now a major pillar of the nascent tourism strategy of 
many countries. Cultural/heritage tourism strategies in various countries have in common that they are a major growth area, that they can be used to boost local culture and that they can aid the seasonal and geographic spread of tourism (Richards, 1996).

As tourists are becoming more sophisticated, their need to recapture the past has increased. Tourists have been visiting cultural/heritage sites more frequently. Following Huh (2002), cultural/heritage tourism offers several benefits to tourists and residents, as well as governments. First of all, cultural/heritage tourism protects historic, cultural, and natural resources in communities, towns, and cities. Second, cultural/heritage tourism educates residents and tourists about local/regional history and traditions. Through the research about and development of heritage/cultural destinations, residents will become better informed about local/regional history and traditions which can be shared with tourists. Third, cultural/heritage tourism builds closer, stronger communities. Knowledge of heritage provides continuity and context for communities, which instils respect in their residents, strengthens citizenship values, builds community pride, and improves quality of life. Fourth, cultural/heritage tourism promotes the economic and civic vitality of a community or region. Economic benefits include: the creation of new jobs in the travel industry, at cultural attractions, and in travel-related establishments; economic diversification in the service industry (restaurants, hotels/motels, bed-and-breakfasts, tour guide services), manufacturing (arts and crafts, souvenirs, publications), and agriculture (specialty gardens or farmers' markets); encouragement of local ownership of small businesses; higher property values; increased retail sales; and substantial tax revenues.

In general, satisfying customers is important from different perspectives. Research has shown that satisfaction can affect customer retention and also lead them to recommend the goods or services to others. And this can be applied to tourism. So, it is crucial to investigate which factors are important for tourists. Furthermore, tourist satisfaction usually contributes to increased rates of tourist patronage, loyalty and acquisition retention, which in turn helps to achieve economic goals such as increasing the number of tourists and revenues. These factors, among others, are the reason why tourist satisfaction is a subject that is worth being studied (Akama et al., 2002).

Quality management theories indicate that many key product and service attributes have a non linear relationship with satisfaction (Conklin et al., 2002). Most of the studies conducted to evaluate consumer satisfaction have utilised models of expectation/disconfirmation (Franchen and Van Raaij, 1981), equity (Fisk and Young, 1985), norm (Cadotte et al., 1987) and perceived overall performance (Tse and Wilton, 1988). Nevertheless, it has been recently proposed that not only the cognitions -such as expectations and disconfirmation- but also emotions can play an important role in satisfaction formation (see, Oliver, 1993; Yu and Dean, 2001; Van Dolen et al., 2004, and Rodriguez and San Martin, 2008, among others). Even a cognitive-affective view has been recently proposed, where satisfaction is influenced by the individual's cognitive judgements and emotions derived from the consumption experience (Phillips and Baumgartner, 2002, Bigné et al., 2005, and Rodriguez and San Martin, 2008, are good examples).

Focussing in the expectation/disconfirmation model, consumers develop expectations about a product or service before purchasing. Subsequently, they compare actual performance with those expectations. Tourists, like others customers, usually have initial expectations of the type and quality of services to be offered at a particular destination. The extent to which tourist expectations are met will eventually determine the level of tourist satisfaction. If the overall performance, while or after visiting a destination, exceeds or meets initial expectations, then the tourist is considered satisfied. Otherwise, the tourist may be dissatisfied. At this point, an interesting aspect of the expectation/disconfirmation model is to test the hypothesis of independence between expectations and disconfirmation versus what we call the positive version of the assimilation theory. According to the assimilation theory (Sherif and Hovland, 1961), individuals suffer a psychological conflict when they perceive discrepancies between performance and prior beliefs and they tend to adjust perceptions to their expectations in order to minimise, or even remove, that tension (Oliver, 1997). What we call the positive version of the assimilation theory states that in case of high expectations individuals tend to over adjust satisfaction (slight positive disconfirmation), and in case of lower expectations the tendency is to a slight under adjusting. In these circumstances, expectations are a driver of satisfaction.

This is the specific point of the expectation/disconfirmation strategy we are going to revisit in this article. Our contribution consists in a statistical way of testing the hypothesis of independence between expectations and 
slight disconfirmation versus the positive version of the assimilation theory. We propose a derivation of the chisquare test including an asymmetric continuity correction to determine the existence of association between expectations (low, high) and slight disconfirmation (negative, positive) in tourist attributes. In case that the hypothesis of independence is rejected and the association is positive, the positive version of the assimilation theory could be at work, and it means that satisfaction could be underestimated (in case of a large percentage of visitors with low expectations) or overestimated (when there is a great percentage of tourist with high expectations). A study case has been carried out in the emblematic old quarter of Toledo, Spain (a UNESCO World Heritage City).

The reminder of the paper is structured as follows. Section 2 presents the technical details of the novel statistical test. Section 3 describes the case study (study site and dataset). Section 4 reports the main results obtained from the application of the proposed statistical novelty to test the Assimilation Theory. The paper ends with some concluding remarks.

\section{TESTING INDEPENDENCE BETWEEN SATISFACTION AND DISCONFIRMATION VERSUS THE POSITIVE VERSION OF THE ASSIMILATION THEORY: A CHI-SQUARED TEST WITH AN ASYMMETRIC CONTINUITY CORRECTION.}

As said before, according to the positive version of the assimilation theory, individuals suffer a psychological conflict when they perceive discrepancies between performance and prior beliefs and they tend to slightly under adjust (in case of low expectations) or over adjust (in case of high expectations) perceptions to their expectations in order to minimise, or even remove, that tension. In these circumstances, expectations are a driver of satisfaction and, as a consequence, this is a core aspect to be studied.

An attractive way to check whether the empirical evidence favours the positive version of the assimilation theory assimilation theory in the field of tourism is to test the hypothesis of independence between the labels of factors "expectancy" (low, high) and "slight disconfirmation" (negative, positive).

Should the independence hypothesis be rejected, positive association will indicate that high expectations are related to slight positive disconfirmation and low expectations to slight negative disconfirmation; negative association can be understood as the relationship between high expectations and slight negative disconfirmation and low expectations and slight positive disconfirmation. That is, positive association implies a slight exacerbation of expectations and favours the positive version of the assimilation theory, while negative association means correction of expectations and does not favour the positive version of the theory (in case of high expectations things are not as good as expected, but in case of low expectancy things are not as bad as expected). An immediate consequence of the positive version of the assimilation theory in the case of cultural/heritage tourism (where expectations usually are high) is the over estimation of the satisfaction score.

From the perspective of the qualitative statistics, The chi-square test of independence is the instrument it should be used for this purpose, as it provides an approximation to the so-called "exact probability" (the probability of having a result equal to or more distanced from the hypothesis of independence than the sample result). But, as shown in Montero (2002), such an "approximation" is certainly poor in case that the number of questionnaires is not sufficiently large.

This is why in this article the "exact probability" will be approximated by including an asymmetric continuity correction in the chi-square statistic. As shown in Montero (2002), this asymmetric correction for continuity works better than Mantel (1974) and Cochran (1942) corrections the underestimations and overestimations of the exact probability provided by the usual Yates (1934) correction. Some technicalities are given next in the framework of $(2 \times 2)$ tables. Generalisation to (RXC) tables is straightforward.

The proposed strategy for assessing the probability of observing a table differing to the same extent or more from the independence hypothesis than that observed is as follows (fixed margins, as usual, are assumed): Let $n_{i j}$ and $\hat{E}_{i j}$ be the observed and expected frequencies (under the null), respectively, in a chosen cell $\{i j\}$ of a (2x2) contingency table. Then, 


$$
P_{\text {exact }} \approx\left\{\begin{array}{l}
P\left(N_{i j} \leq n_{i j}+\frac{1}{2}\right)+P\left(N_{i j} \geq 2 \hat{E}_{i j}-n_{i j}+\Delta\right) \text { in case that } n_{i j} \leq \hat{E}_{i j} \\
P\left(N_{i j} \geq 2 \hat{E}_{i j}-n_{i j}+\Delta\right)+P\left(N_{i j} \leq n_{i j}+\frac{1}{2}\right) \text { in case that } n_{i j}>\hat{E}_{i j}
\end{array}\right.
$$

where

$$
N_{i j} \stackrel{\text { aprox }}{\longrightarrow} N\left(\frac{n_{i \bullet} n_{\bullet j}}{n} ; \sqrt{\frac{n_{1 \bullet} n_{2 \cdot} n_{\bullet 1} n_{\bullet 2}}{n^{2}(n-1)}}\right)
$$

That is to say,

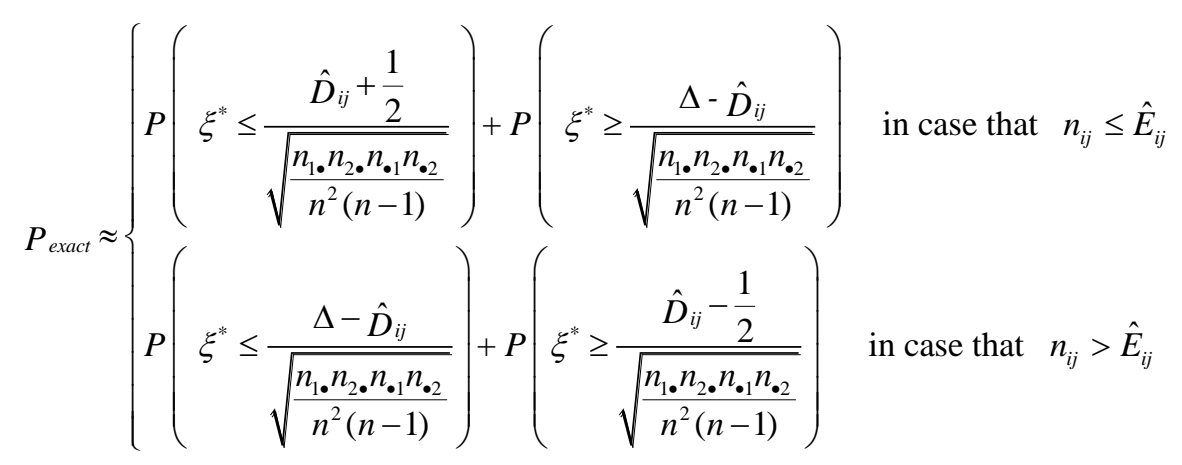

where $\xi^{*}$ is a Gaussian distribution with zero mean and unit variance, $\hat{D}_{i j}=n_{i j}-\hat{E}_{i j}$, and $\Delta$ is a quantity that must be computed as follow:

1. Take the integer part of $2 \hat{E}_{i j}-n_{i j}$.

2. Add 0.5 to the above quantity and denote by $\theta$ the resulting value.

3. Obtain $\Delta$ from the equation $\Delta=\theta-2 \hat{E}_{i j}+n_{i j}$.

It is necessary to set two exceptions to the above rule:

In case that $2 \hat{E}_{i j}-n_{i j} \leq \min \left(n_{1 \bullet} n_{2 \bullet} n_{\bullet \mathbf{1}} n_{\bullet 2}\right)$, then $P\left(\xi^{*} \geq \frac{\Delta-\hat{D}_{i j}}{\sqrt{\frac{n_{1 \cdot} n_{2 \bullet} n_{\bullet 1} n_{\bullet 2}}{n^{2}(n-1)}}}\right)=0$.

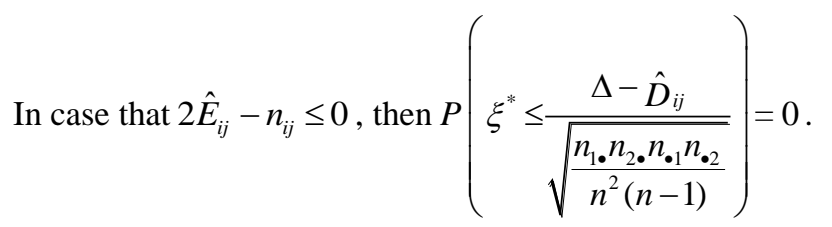

Finally, the independence test is carried out by comparing the corresponding probability (depending on the case) to the level of significance. If the independence hypothesis is rejected, the intensity and direction of the association, measured by the $Q$ Yule's value,

$$
Q=\frac{n_{11} n_{22}-n_{12} n_{21}}{n_{11} n_{22}+n_{12} n_{21}}
$$

will indicate if the empirical evidence favours the positive version of the assimilation theory. 


\section{CASE STUDY}

\subsection{Study site}

The case study was carried out in the emblematic old quarter of Toledo, in Spain. Toledo is a UNESCO World Heritage City with an economy driven to a significant extent by commercial activities deriving from tourism.

The city of Toledo (pop. 76,618 as of 2009) is located in central Spain, about $71 \mathrm{~km}$ from the capital city of Madrid. Toledo was the imperial capital until 1563 when the court moved to Madrid, and is currently the seat of the regional government of Castilla-La Mancha, one of the most extensive regions in the country. As a medieval city known today as the city of the three cultures due to its Islamic, Christian, and Jewish heritage, Toledo has been highly successful in the task of preserving its historical and architectural character. This accomplishment has been recognised by the UNESCO, which has granted the denomination of World Heritage City. The preservation of centuries-old city walls has meant that Toledo has experienced relatively little expansion, with virtually all recent growth taking place beyond the perimeter of the old city (see Figure 1). Given its historical and cultural interest, its proximity to Madrid and excellent connections with the capital and other regions, which include highways and a new High Speed Train service, Toledo has benefited from a very active tourist sector, and related commercial and service activities. The service sector and tourism in particular, is enormously important for the economy of the city, with the former accounting for about $84.5 \%$ of Toledo's gross product, half of which is due to tourism. The importance of these activities is also reflected by the distribution of the economically active population in the municipality, $86.5 \%$ of which is linked to the service sector. According to Esteban et al. (2005), some $45 \%$ of visitors to the city are international travellers. In terms of expenditure in the city, about $80 \%$ of all visitors (domestic and international) have a daily budget per person of between 50 and 100 Euros, while about $14 \%$ have a budget of between 100 and 200 Euros. Besides accommodation, other significant expenses include food and beverages, clothing and shoes and souvenirs. There are about 11,000 establishments in the city that cater to the demand for these services.

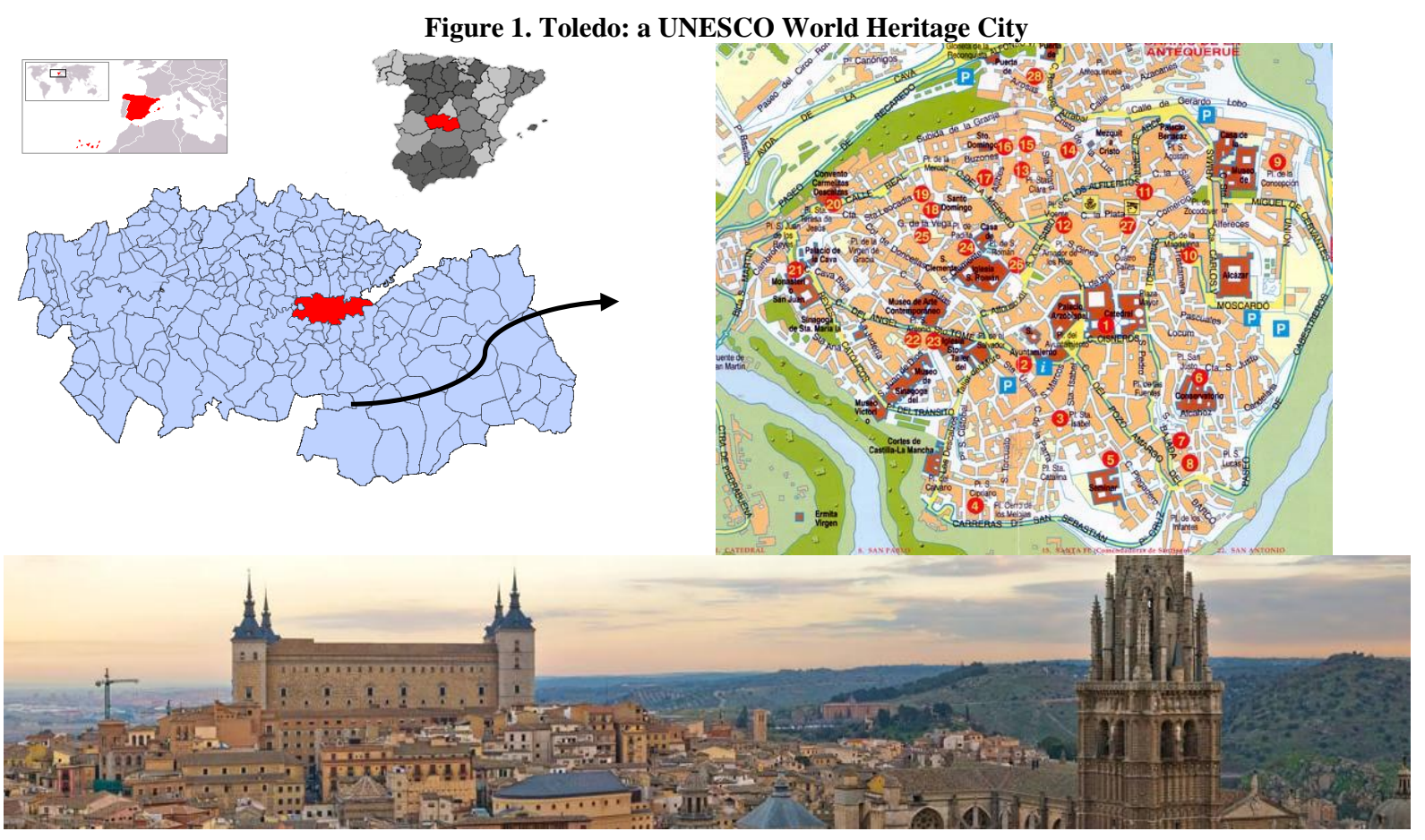




\subsection{Data set}

The information has been collected by means of a specially developed questionnaire, the type of survey being a personal interview.

Data were collected during the months of April, May and June, 2009. A total of 1,500 questionnaires were completed. Statistical analysis of questionnaires revealed no significant differences among them, this being the reason why the set of polled tourists can be considered a unique sample of tourists. Tourists were interviewed in different locations of the old quarter of Toledo city (monuments, squares, restaurants, hotels, etc.) at different hours, to try to collect as wide a range of people and situations as possible.

The questionnaire included the following tourist attributes: accommodation, tourist attractions and or/ walks, entertainment/ cultural and recreational activities, food, shopping, cleanliness, hygiene, public toilets, Internet/ communications/ phone, public lightning, hospitality, information, security, tourist information offices, providers of tourist services, public transport connections, signposting, banks/ ATM, local transport, environmental care, accessibility, and ability to settle problems. The non-response rate was $6.8 \%$, and most of the non-respondents were Asian people.

Although the population of visitors is unknown, we can infer the appropriateness of the sample from indirect indicators such as percentage of male and female, percentage per age strata, percentage per nationality, etc. The structure of these percentages is very similar to official data (if available).

Table 1. Technical Data

\begin{tabular}{l|l}
\hline Population & About 600,000 tourist \\
Geographical Area: & Toledo City \\
Sample size: & 1,500 \\
Sample error: & $\pm 5.1 \%$ \\
Significance level: & $5 \%$ \\
Sample period: & April, May and June 2009 \\
\hline
\end{tabular}

Source: Own elaboration

Table 2. Global overall tourist satisfaction

\begin{tabular}{|c|c|c|}
\hline Attribute & $\begin{array}{l}\text { Weight } \\
\lambda_{i}\end{array}$ & $\begin{array}{l}\text { Score } \\
\bar{P}\end{array}$ \\
\hline Accommodation & 0.061 & 6.950 \\
\hline Tourist attractions and or/ walks & 0.102 & 7.683 \\
\hline Entertainment/ cultural and recreational activities & 0.073 & 6.907 \\
\hline Food & 0.073 & 7.390 \\
\hline Shopping & 0.047 & 6.477 \\
\hline Cleanliness, hygiene, public toilets & 0.051 & 6.301 \\
\hline Internet/ Communications/ Phone & 0.040 & 6.127 \\
\hline Public lightning & 0.036 & 6.483 \\
\hline Hospitality & 0.054 & 6.937 \\
\hline Information & 0.048 & 6.863 \\
\hline Security & 0.050 & 6.809 \\
\hline Tourist information offices & 0.047 & 6.560 \\
\hline Providers of tourist services & 0.045 & 6.363 \\
\hline Public transport connections & 0.041 & 6.577 \\
\hline Signposting & 0.037 & 6.303 \\
\hline Banks/ ATM & 0.037 & 6.303 \\
\hline Local transport & 0.039 & 6.250 \\
\hline Environmental care & 0.040 & 6.567 \\
\hline Accessibility & 0.041 & 6.277 \\
\hline Ability to settle problems & 0.036 & 6.120 \\
\hline Global overall tourist satisfaction level & & 7.150 \\
\hline
\end{tabular}

Source: Own elaboration 


\section{RESULTS}

In this section the hypothesis of independence between expectations and slight disconfirmation is tested versus the positive version of the assimilation theory by using a new version of the Chi-square test that includes an asymmetric correction for continuity.

The overall level of tourist satisfaction scores 7.15 (maximum mark is 10), which can be considered an excellent mark (Table 2). Note that the most important attributes for Toledo visitors are "Tourist attractions and or/ walks" (weight of 10.2/100); "Entertainment/ cultural and recreational activities" and "Food", each weighted 7.2/100; "Accommodation" with 6.1/100, "Shopping", "Cleanliness, hygiene, and public toilets", "Hospitality", "Information", "Security", "Tourist information offices" and "Providers of tourist services" have a weight of around $5 / 100$; and the importance given to the rest of services ranges from 3.6/100 to 4.5/100.

Having said that, when we deal with testing the hypothesis of independence between expectations and slight disconfirmation versus the positive version of the assimilation theory by using a new version of the Chi-square test that includes an asymmetric correction for continuity (Table 3), it can be observed that in all cases, except "Entertainment/ cultural and recreational activities", "Public lightning", and "Signposting", the hypothesis of independence between expectancy (low, high) and slight disconfirmation (negative, positive) has been rejected at a 0.05 significance level. In the rest of cases, the Yule's Q value is positive. Therefore, positive association exists, which indicates the relationship of high expectations with slight positive disconfirmation and low expectations with slight negative disconfirmation. That is, positive association implies a moderate exacerbation of expectations and rejects the null in favour of the positive version of the assimilation theory, and consequently expectations could be considered a driver of satisfaction. As can be appreciated in Table 3, the most important attributes for tourist are included in the group with highest Q value (that is headed by "Accommodation"). A factor confirmation of positive association has been computed as the ratio "percentage of respondents with low or high expectations/ percentage of total respondents" to avoid cases in which positive association is based on a small percentage of respondents with low or high expectations. As it can be observed in Table 3, all confirmation factors are above $60 \%$, except in the attribute relative to "Providers of tourist services". Therefore, in this case, despite having detected positive association, the obtained result should be considered with caution.

Table 3. A Chi-squared test with an asymmetric correction for continuity

\begin{tabular}{|c|c|c|c|c|c|c|}
\hline \multicolumn{4}{|c|}{$n_{11}>\hat{E}_{11}$ (all cases) } & \multirow{2}{*}{$\begin{array}{l}\text { Yule's } \\
\text { Q value }\end{array}$} & \multirow{2}{*}{$\begin{array}{l}\text { Confirmation of the } \\
\text { positive version of the } \\
\text { assimilation theory }\end{array}$} & \multirow{2}{*}{$\begin{array}{c}\text { Confirmation } \\
\text { factor }\end{array}$} \\
\hline Attribute & $\mathbf{P}^{(1)}$ & $\mathbf{P}^{(2)}$ & $\begin{array}{c}\text { Exact } \\
\text { Probability } \\
\end{array}$ & & & \\
\hline Accommodation & 0.0000 & 0.0000 & $0.0000^{*}$ & 0.60 & Yes & 0.72 \\
\hline Tourist attractions and or/ walks & 0.0000 & 0.0000 & $0.0000 *$ & 0.34 & Yes & 0.83 \\
\hline $\begin{array}{l}\text { Entertainment/ cultural and } \\
\text { recreational activities }\end{array}$ & 0.0901 & 0.0025 & 0.1151 & 0.11 & No & 0.65 \\
\hline Food & 0.0000 & 0.0000 & $0.0000 *$ & 0.34 & Yes & 0.82 \\
\hline Shopping & 0.0006 & 0.0010 & $0.0016^{*}$ & 0.34 & Yes & 0.69 \\
\hline Cleanliness, hygiene, public toilets & 0.0150 & 0.0174 & $0.0324 *$ & 0.24 & Yes & 0.65 \\
\hline Internet/ Communications/ Phone & 0.0011 & 0.0019 & $0.0030 *$ & 0.35 & Yes & 0.61 \\
\hline Public lightning & 0.0793 & 0.0869 & 0,1662 & 0.16 & No & 0.70 \\
\hline Hospitality & 0.0000 & 0.0000 & $0.0000^{*}$ & 0.33 & Yes & 0.75 \\
\hline Information & 0.0026 & 0.0025 & $0.0051 *$ & 0.31 & Yes & 0.76 \\
\hline Security & 0.0000 & 0.0000 & $0.0000 *$ & 0.42 & Yes & 0.64 \\
\hline Tourist information offices & 0.0019 & 0.0020 & $0.0039 *$ & 0.30 & Yes & 0.78 \\
\hline Providers of tourist services & 0.0000 & 0.0000 & $0.0000 *$ & 0.83 & Yes & 0.27 \\
\hline Public transport connections & 0.0009 & 0.0013 & $0.0022 *$ & 0.29 & Yes & 0.61 \\
\hline Signposting & 0.0256 & 0.0287 & 0.0543 & 0.21 & No & 0.65 \\
\hline Banks/ ATM & 0.0122 & 0.0192 & $0.0314 *$ & 0.24 & Yes & 0.63 \\
\hline Local transport & 0.0000 & 0.0000 & $0.0000 *$ & 0.41 & Yes & 063 \\
\hline Environmental care & 0.0011 & 0.0011 & 0.0022 & 0.31 & Yes & 0.68 \\
\hline Accessibility & 0.0006 & 0.0011 & $0.0017 *$ & 0.36 & Yes & 0.67 \\
\hline Ability to settle problems & 0.0000 & 0.0004 & $0.0004 *$ & 0.43 & Yes & 0.63 \\
\hline
\end{tabular}

Source: own elaboration.

* Significant at 0.05 significance level. 


$$
p^{(1)}=P\left(N_{i j} \leq 2 \hat{E}_{11}-n_{11}+\Delta\right) ; \quad p^{(2)}=P\left(N_{11} \geq n_{11}-\frac{1}{2}\right) ; \quad \hat{E}_{11}=\frac{n_{1 \bullet} n_{\bullet 1}}{n}
$$

\section{CONCLUSION}

Cultural/heritage tourism is the fastest growing segment of the tourism industry, and obviously, the growth in the cultural/heritage tourism market may provide several benefits to cultural/heritage destinations. Because of people's inclination to seek out novel attractions, including traditional cultures, heritage tourism has become a major "new" area of tourism demand, which almost all policy-makers are now aware of and anxious to develop. Heritage tourism, as part of the broader category of "cultural tourism", is now a major pillar of the nascent tourism strategy of many countries. Cultural/heritage tourism strategies in various countries share the fact that they are a major growth area, that they can be used to boost local culture and that they can aid the seasonal and geographic spread of tourism.

In this article it has been revisited the assimilation theory in the framework of the expectations/disconfirmation paradigm. In particular, it has been proposed a derivation of the chi-square test that includes an asymmetric correction for continuity to test the hypothesis of independence between expectations and moderate disconfirmation versus the positive version of the assimilation theory in tourist attributes. This novelty has been incorporated into a Spanish tourist case study: the emblematic old quarter of Toledo, which is a UNESCO World Heritage City with an economy driven to a significant extent by commercial activities deriving from tourism.

Independence between the levels of both the factors "expectations" and "slight disconfirmation" has been rejected in favour of the positive version of the assimilation theory in 17 out of the 20 attributes included in the questionnaire. Only in "Entertainment/ cultural and recreational activities", "Public lightning", and "Signposting", the hypothesis of independence between expectations (low, high) and moderate disconfirmation (negative, positive) was not rejected at a 0.05 significance level.

In all the remainder cases the sign of the Yule's $Q$ value has been positive, what means, in the studied destination, a slight exacerbation of expectations. Additionally, all confirmation factors are above 60\%, except in the attribute relative to "Providers of tourist services". Therefore, in this case, despite having detected positive association, this result should be considered with caution. There have not been found any case of negative association, that is to say, in case of high expectations things are not as good as expected, but in case of low expectancy things are not as bad as expected.

Results are highly positive for Toledo, because the overall level of tourist satisfaction scored 7.15 (maximum mark is 10), which can be considered an excellent mark, and satisfaction exceeded expectations (the only two dissatisfying attributes -satisfaction does not reach expectations- are "Internet/ Communications/ Phone" and "Providers of tourist services"). Moreover, the linear regression of the mean satisfaction relative to the weight of the considered attributes indicates that the more important an attribute is for tourists, the higher their level of satisfaction. In particular, an increase of one unit in the scale of importance leads to a rise of 0.22 in the level of satisfaction with such an attribute. However, as the hypothesis of independence between expectations and moderate disconfirmation does not hold in the case of Toledo and for most attributes the $Q$ value is positive, which favours the alternative that it is working the positive version of the assimilation theory, satisfaction could be overestimated due that the percentage of individuals with high expectations for most of the considered attributes exceeds $80 \%$ (as expected in a cultural/heritage city).

\section{AUTHOR INFORMATION}

José-María Montero: He is PhD in Economics and Business Administration, Autonomous University of Madrid, Spain. Currently his position is Full Professor in Statistics at the Department of Statistics, Faculty of Law and Social Sciences, University of Castilla-La Mancha, Spain. E-mail: Jose.MLorenzo@ uclm.es.

Research Interest: qualitative data, geostatistics and tourism. 
Gema Fernández-Avilés: She is European $\mathrm{PhD}$ in Economics and Business Administration, University of CastillaLa Mancha, Spain. Currently his position is Assistant Professor in Statistics at the Department of Statistics, Faculty of Law and Social Sciences, University of Castilla-La Mancha, Spain. E-mail: Gema.FAviles@uclm.es.

Research Interest: qualitative data, geostatistics and tourism.

\section{REFERENCES}

1. Akama, J. S., and Mukethe-Kieti, D. (2002). Measuring tourists' satisfaction with Kenya safari. Tourism management, 24, 73-81.

2. Bigné, E., Andreu, L. and Gnoth, J. (2005). The Theme Park Experience: An Analysis of Pleasure, Arousal and Satisfaction. Tourism Management, 26, 833-844.

3. Cadotte, E. R., Woodruff, R. B., and Roger L. J. (1987). Expectations and Norms in Models of Consumer Satisfaction. Journal of Marketing Research, 24, 305-314.

4. Cochran, W.G. (1942). The 2x2 correction continuity. Iowa State College Journal, 16, 421-436.

5. Conklin, P., Powaga, K., and Lipovetsky, S. (2002). Customer satisfaction analysis: Identification of key drivers. European journal of operational research, 154, 819- 827.

6. Cooper, C., Fletcher, J., Wanhill, S., and Gilbert, D. (2008). Tourism: Principles and Practice. (3rd ed.). Harllow: Pearson Education.

7. Esteban, A., Martín- Consuegra, D., Molina, A. and Díaz, E. (2005). Turismo y consumo: El caso de Toledo. Centro de Estudios de Consumo de la Universidad de Castilla- La Mancha y de la Junta de Comunidades de Castilla- La Mancha. Working paper. Toledo

8. $\quad$ Fisk, R.P., and Young, C.E. (1985). Disconfirmation of equity expectations: Effects of consumer satisfaction with services. In Hirchman, E.C. and Holbrook, M. (Eds.). Advances in consumer research. Vol.12 (pp. 340-345). Provo, UT: Association for Consumer Research.

9. Francken, D.A., and Van Raaij, W.J. (1981). Satisfaction with leisure time activities. Journal of Leisure Research, 13(4), 337-352.

10. Haber, S. and Lerner, M. (1998). Correlates of Tourist Satisfaction. Annals of Tourism Research, 25(4), 197-201.

11. Huh, J. (2002). Tourist satisfaction with cultural/heritage sites: The Virginia Historic Triangle. Thesis for the degree of Master of Sciences in Hospitality and Tourism Management. Virginia Polytechnic Institute and State University.

12. Mantel, N. (1974). Some reasons for not using the Yates continuity correction in $2 x 2$ contingency tables. Comment and a suggestion. Journal of the American Statistical Association, 69, 378-380.

13. Montero, J.M. (2002). Una propuesta de corrección de continuidad asimétrica para tablas de contingencia (2x2) con totales marginales fijos". Estadística española. 44, (149), 29-46.

14. Oliver, R. L. (1993). Cognitive, Affective, and Attribute Bases of the Satisfaction Response. Journal of Consumer Research, 20, 418-430.

15. Oliver, R.L. (1997). Satisfaction: A Behavioral Perpective on the Consumer. New York: Mc Graw- Hill.

16. Phillips, D. and Baumgartner, H. (2002). The Role of Consumption Emotions in the Satisfaction Response. Journal of Consumer Psychology, 12, 243-52.

17. Richards, G. (1996). Production and consumption of cultural tourism in Europe. Annals of Tourism Research, 23(2), 261-283.

18. Rodríguez, I., and San Martín, H. (2008). Tourist Satisfaction. A congnitive-afective model. Annals of Tourism Research, 35 (2), 551-573.

19. Sherif, M. and Hovland, C. I. (1961). Social judgment: Assimilation and contrast effects in communication and attitude change. New Haven: Yale University Press.

20. Tse, D. K., and Wilton, P. C. (1988). Models of Consumer Satisfaction Formation: An Extension, Journal of Marketing Research, 25, 204-212.

21. Van Dolen, W., De Ruyter, K., and Lemmink, J. (2004). An Empirical Assessment of the Influence of Customer Emotions and Contact Employee Performance on Encounter and Relationship Satisfaction. Journal of Business Research, 57, 437-444.

22. WTTC (2006). http://www.wttc.org.

23. Yates, F. (1934). Contingency tables involving small numbers and the chi-squared test. Journal of the Royal Statistical Society, 1, 217-235. 
24. Yu, Y. and Dean, A. (2001). The Contribution of Emotional Satisfaction to Consumer Loyalty. International Journal of Service Industry Management, 12, 234-250.

\section{NOTES}

